\title{
INTERICTAL ELECTROENCEPHALOGRAPHIC FINDINGS IN CHILDREN AND ADULTS WITH TEMPORAL LOBE TUMORS
}

\author{
Renata C. Franzon', Maria Augusta Montenegro², Clarissa Lin Yasuda', \\ Catarina A. Guimarães ${ }^{1}$, Carlos A.M. Guerreiro ${ }^{3}$, Fernando Cendes ${ }^{3}$, \\ Kette D. Valente², Marilisa M. Guerreiro ${ }^{3}$
}

\begin{abstract}
Objective: To characterize clinical and interictal electroencephalographic aspects of childre $n$ and adults with temporal lobe epilepsy (TLE) due to tumoral lesions. Method: We perf o rmed a retrospective analysis of the clinical and interictal electroencephalographic aspects of 16 children (64 exams) and 12 adults (78 exams) with lesions in the temporal lobe. Results: The most frequent etiologies were gangliogliomas, DNETs, followed by astrocytomas. Auras occurred in both groups, the most common being epigastric sensation. Other findings such as myoclonias, behavioral arrest and vomiting were more frequent in children. Temporal epileptiform and nonepileptiform activities, mostly unilateral, were found in both groups. Extratemporal epileptiform activities (frontal, parietal, central, occipital and generalized) were also found equally in both groups. Conclusion: Our data show that children and adults with TLE due to expansive lesions present with similar EEG findings.
\end{abstract}

KEY WORDS: epilepsy, childhood, temporal lobe, EEG, tumors.

\section{Eletrencefalograma interictal em crianças e adultos com tumores de lobo temporal}

RESUMO - Objetivo: Avaliar os aspectos eletrencefalográficos interictais e clínicos de crianças e adultos com epilepsia do lobo temporal secundária a lesões tumorais. Método: Análise re trospectiva dos aspectos clínicos e eletrencefalográficos interictais de 16 crianças (64 exames) e 12 adultos (78 exames) com lesões tumorais no lobo temporal. Resultados: As etiologias mais freqüentes foram gangliogliomas e DNETs, seguidos por astrocitomas. As auras ocorreram em ambos os grupos, sendo a sensação epigástrica a mais comum. Outros achados tais como mioclonias, parada comportamental e vômitos foram mais freqüentes em crianças. Atividade epileptiforme e não epileptiforme temporal, principalmente unilateral, foi encontrada nos dois grupos. Atividade epileptiforme extra temporal (frontal, parietal, central, occipital e generalizada) foi também igualmente detectada em ambos os grupos. Conclusão: Crianças e adultos com epilepsia do lobo temporal secundária a lesões tumorais apresentam padrão eletrencefalográfico semeIhante.

PALAVRAS-CHAVE: epilepsia, lobo temporal, EEG, tumores.

Due to a wider use of magnetic resonance imaging (MRI), neurodevelopmental tumors have been diagnosed with increasing frequency as a cause of refractorytemporal lobe epilepsy (TLE), especially in children. In some studies, they are considered the main cause of refractory TLE in children ${ }^{1,2}$. The tumors most frequently found are neuronal or glioneural tumors (gangliogliomas, gangliogliocytoma, ganglioneuroma, dysembryoplastic neuroepithelial tumor DNET), oligodendrogliomas and astrocytomas, includ- ing pleomorphic xanthoastrocytoma. Gangliogliomas are the main tumors responsible for the occurrence of epileptic seizures which are difficult control with medications, and which have an onset before the age of fifteen ${ }^{3}$. They are tumors of slow growth and there is an absence of clinical signs of localization and also the absence of signs of intracranial hypertension ${ }^{4}$.

The growth of those tumors and their pathological findings suggest that they, particularly gangli-

Departamento de Neurologia, Universidade Estadual de Campinas (Unicamp) e Laboratório de Neurofisiologia Clínica, Instituto de Psiquiatria, Universidade de São Paulo (USP), Brazil: 'Pós-Graduanda; ${ }^{2}$ Professora Doutora; ${ }^{3}$ Professor Associado.

Received 21 November 2005. Accepted 14 March 2006.

Dra. Marilisa M. Guerreiro - Departmento de Neurologia - FCM - Unicamp / Caixa Postal 6111 - $13083-970$ Campinas SP - Brasil. E-mail: mmg@fcm.unicamp.br 
ogliomas and DNET, might either originate from a cortical malformation or be the final end of the spect rum of the cortical dysplasias ${ }^{5-9}$. In children with TLE of diffe rent etiologies there is a wide clinico-electroencephalographic diversity ${ }^{2,10-13}$.

Knowing that tumoral lesions lead to a variable electrencephalographic pattern, particularly in chil$d$ ren, we aimed to compare interictal EEG findings of children with those of adults with TLE due to tumoral lesions.

\section{METHOD}

We perf ormed a re $t$ rospective analysis of 16 patients (9M:7F) younger than 17 years of age (mean age: 10 years) with an expansive lesion in the temporal lobe, who were followed at the childhood epilepsy clinic of the HC/Unicamp and of the Institute of Psychiatry/U SP, from 1998 to 2005 (Group 1).

The interictal electroencephalographic fi ndings were com pared to those of 12 adult patients (6M:6F), from 21 to 51 years of age, followed at the ambulatory clinic of epilepsy of difficult medical control of the HC/Unicamp (Group 2).

Two to 11 routine EEGs were recorded in each patient, following the international rules for electrodes placement: "system 10-20". Two EEG devices were used, one with 14 channels (analog) and another with 32 channels (digital), both from Nihon Kohden Company. The montages were in accordance with the American EEG Society, using montages with zygomatic electrodes besides bipolar montages (Iongitudinal and transverse) and re fe rential with the vertex. The minimal duration of the tracings was 20 minutes. The examinations were perf o rmed during sleep, somnolence and while awake. Methods of activation (hyperventilation and intermittent photic stimulation) were routinely used. In younger children and in those less collaborative, whenever necessary, the sleep phase was induced with chloral hydrate.

Telemetry was performed in nine children and six adults.

We used the t-student and Fisher tests for statistical analysis.

\section{RESULTS}

The mean age of onset of the epileptic seizures was 16.1 years in the adult patients and 6.4 years in the children, which is statistically significant $(p=0.01)$.

Simple partial seizures occurred in nine children and in 11 adults, being predominantly epigastric and visual aura. There were complex manual automatisms in nine patients of the groups 1 and 2 (56\% and 75\%, respectively). Other findings, such as myoclonias (two child ren), behavioral arrest at the beginning of the ictus (six children and two adults), and vomiting (four
Table 1. Etiology-neuropathological data.

\begin{tabular}{lcc}
\hline Neuropathological findings & Children & Adults \\
\hline Ganglioglioma & 6 & 3 \\
DNET & 4 & 0 \\
Astrocytoma & 0 & 1 \\
Pilocytic astrocytoma & 1 & 0 \\
Cavernoma & 1 & 1 \\
Ruptured epidermic cyst & 0 & 1 \\
Without definition & 4 & 6 \\
\hline
\end{tabular}

Table 2. Interictal EEGs with temporal discharges (in numbers).

\begin{tabular}{lccc}
\hline & Children & Adults & $\mathrm{p}$ \\
\hline Temporal EA & 15 & 9 & 0.285 \\
Contralateral temporal EA & 3 & 5 & 0.230 \\
Bilateral temporal EA & 6 & 4 & 1 \\
Temporal NEA & 13 & 7 & 0.230 \\
Bilateral t NEA & 5 & 5 & 0.697 \\
Contralateral temporal NEA & 0 & 3 & 0.067 \\
Normal & 4 & 9 & 0.020 \\
\hline
\end{tabular}

EA, epileptiform activity; NEA, nonepileptiform activity.

Table 3. Interictal EEGs with extratemporal discharges (in numbers).

\begin{tabular}{lccc}
\hline & Children & Adults & $\mathrm{p}$ \\
\hline Frontal & 4 & 2 & 0.673 \\
Parietal & 4 & 2 & 0.673 \\
Occipital & 2 & 0 & 0.492 \\
Central & 4 & 3 & 1 \\
Generalized & 3 & 0 & 0.238 \\
\hline
\end{tabular}


children and two adults) were more frequent in children, and there was no significant difference between the two groups in signs and symptoms.

The neuropathological data of the patients who had already undergone surg e ry are shown in Table 1 (12 children and six adults).

The most frequent etiologies were ganglioglioma, DNET, followed by astrocytoma. We found six temporal mesial lesions in the children and six in the adults, and there were 10 lateral lesions in the children and six in the adults. The lesions occurred most frequently in the right hemisphere: 10 children and eight adults.

Table 2 shows the temporal EEG findings of groups 1 and 2 . The childhood group (Group 1) underwent 64 exams (mean: 4 exams per patient) and the adult $g$ roup (Group 2) had 78 exams (mean: 6.5 exams per patient).

Table 3 shows the extratemporal EEG findings of groups 1 and 2.

\section{DISCUSSION}

Our data show that temporal interictal epileptiform and nonepileptiform activity occur equally in all age ranges. Normal EEGs were significantly more frequent in the adults in this study. However, according to Harvey et al. ${ }^{14}$, in the pediatric age range, $15.9 \%$ of the patients with TLE may have persistently normal EEGs. Interictal extratemporal epileptiform activity was also found in both groups, which was unexpected, as TLE in childhood usually presents with a greater clinico-electroencephalographic diversity'.

Pre-operative studies performed in adults with temporal lobe tumors have demonstrated electrophysiological variability: temporal focal discharges, bilateral temporal activity, contralateral activity, extratemporal activity and the presence of "mirror focus" $15-22$.

Interictal EEGs of children with TLE may show extratemporal (especially frontal) discharges more frequently than those seen in adults with mesial sclero$\operatorname{sis}^{12}$. In the present study we observed that the EEGs of adult patients with tumoral lesions also displayed extratemporal discharges. That suggests that this ne u rophysiological characteristic might be related to the etiology, independent of the age range. In other words, there was no significant difference between the extratemporal findings of children and adults because both age groups seem to have a similar neurophysiological behavior when the etiology is an expan- sive lesion of the temporal lobe. In patients with TLE caused by hippocampal sclerosis, however, there is a difference between the age ranges ${ }^{12,23}$.

Our data show that seizure onset was significantly earlier in children than in adults, despite the same pathology and similar EEG findings. This may reinforce that EEG features in temporal lobe tumors are not age-dependent.

The clinical features of adults with tumoral lesions in the temporal lobe can be differentiated from those with mesial temporal sclerosis by the initial ictal pattern, by the behavioral sequence and by the time of its appearance during the seizure ${ }^{24}$. Other authors found that seizures of neocortical origin are significantly shorter in duration ${ }^{25}$. In spite of these clinical diffe rences, there is difficulty in making a distinction in an individual patient ${ }^{26}$. Our clinical findings were suggestive of mesial TLE with the presence of typical auras and automatisms, even in the lateral lesions. These findings may either reflect a rapid propagation to the mesial structures or simply occur by the activation of cortical areas distant from the epileptic focus. Few patients presented auras with suggestive of neocortical involvement.

To conclude, this study suggests that interictal discharges in children and adults with TLE due to expansive lesions present with a polymorphic electroencephalographic pattern. Although children with TLE have frequent extratemporal epileptiform discharges, independent of the etiology, there is no significant difference when one compares children and adults with tumoral lesions. In TLE due to mesial sclerosis, there seems to be a difference between the two age groups.

\section{REFERENCES}

1. Duchowny M, Levin B, Jayakar $\mathrm{P}$, et al. Temporal lobectomy in early childhood. Epilepsia 1992;33:298-303.

2. Wyllie E, Chee M, Granstrom ML, et al. Temporal lobe epilepsy in early childhood. Epilepsy 1993;34:859-868.

3. Sutton LN, Roger JP, Rorke LB, Derek AB, Schut L. Cerebral gangliogliomas during childhood. Neurosurgery 1983;13:124-128.

4. Johannsson HJ, Rekate HL, Roessmann U. Gangliogliomas: pathological and clinical correlation. J Neurosurg 1981;54:58-63.

5. Lach B, Duggal N, DaSilva VF, Benoit BG. Association of pleomorphic xanthoastrocytoma with cortical dysplasia and neuronal tumors: a report of three cases. Cancer 1996;78:2551-2563.

6. Madsen JR, Vallat AV, Poussaint TY, Scott RM, De Girolami U, Anthony DC. Focal cortical dysplasia with glioproliferative changes causing seizures: report of three cases. Pediatr Neurosurg 1998;28:261-266.

7. Prayson RA, Estes ML. Dysembryoplastic neuroepithelial tumor. Am J Clin Pathol 1992;97:398-401.

8. Prayson RA, Estes ML, Morris HH. Coexistence of neoplasia and cortical dysplasia in patients presenting with seizures. Epilepsia 1993; 34:609-615. 
9. Shimbo Y, Takahashi H, Hayano M, Kumagai T, Kameyama S. Temporal lobe lesion demonstrating features of dysembryoplastic neuroepithelial tumor and ganglioglioma: a transitional form? Clin Neuropathol 1997;16:65-68.

10. B rockhaus A, Elger CE. Complex partial seizures of temporal lobe origin in children of different age groups. Epilepsia 1995;36:1173-1181.

11. Fogarasi A, Jokeit H, Faveret E, Janszky J, Tuxhorn I. The effect of age on seizure semiology in childhood temporal lobe epilepsy. Epilepsia 2002;43:638-643.

12. Franzon RC, Montenegro MA, Guimarães CA, Guerreiro CA, Cendes F, Guerre i roMM. Clinical, electroencephalographic, and behavioral features of temporal lobe epilepsy in childhood. J Child Neurol 2004; 19:418-423.

13. Nordli DR, Kuroda MM, Hirsch LJ. The ontogeny of partial seizures in infants and young children. Epilepsia 2001;42:986-990.

14. Harvey AS, Berkovic SF, Wrennall JA, et al. Temporal lobe epilepsy in childhood: clinical, EEG, and neuroimaging findings and syndrome classification in a cohort with new-onset seizures. Neurology 1997; 49:960-968.

15. Morrell F, Rasmussen T, Gloor P, De Toledo-Morrell L. Secondary epileptogenic foci in patients with verified temporal lobe tumors. Eletroencephalogr Clin Neurophysiol 1983;54:26.

16. Morris HH, Maltkovic Z, Estes ML, et al. Ganglioglioma and intractable epilepsy: clinical and neurophysiologic features and predictors of outcome after surgery. Epilepsia 1998;39:307-313.

17. Hamer HM, Najm I, Mohamed A, Wyllie E. Interictal epileptiform discharges in temporal lobe epilepsy due to hippocampal sclerosis versus medial temporal lobe tumors. Epilepsia 1999;40:1261-1268.
18. Jo rge CL, Nagahashi-Marie SK, Pedreira CC, et al. Clinical characteristics and surgical outcome of patients with temporal lobe tumors and epilepsy. Arq Neuropsiquiatr 2000;58:1002-1008.

19. Iannelli, Guzzetta F, Battaglia D, Iuvone L, Di Rocco C. Surgical treatment of temporal tumors associated with epilepsy in children. Pediatr Neurosurg 2000;32:248-254.

20. Zaatrh MM, Firlik KS, Spencer DD, Spencer SS. Temporal lobe tumoral epilepsy: characteristics and predictors of surgical outcome. Neurology 2003;61:636-641.

21. Labate A, Briellmann RS, Harvey AS, et al. Temporal lobe dysembryoplastic neuroepithelial tumour: significance of discordant interictal spikes. Epileptic Disord 2004;6:107-114.

22. Sampaio L, Yacubian EM, Manreza ML. The role of mirror focus in the su rgical outcome of patients with indolent temporal lobe tumors. Arq Neuropsiquiatr 2004;62:9-14.

23. Blume WT, Girvin JP, Mclachlan RS, Gilmore BE. Effective temporal lobectomy in childhood without invasive EEG. Epilepsia 1997;38: 164-167.

24. Saygi S, Spencer SS, Scheyer R, Katz A, Mattson R, Spencer DD. Differentiation of temporal lobe ictal behavior associated with hippocampal sclerosis and tumors of temporal lobe. Epilepsia 1994;35:737-742.

25. Foldvary N, Lee N, Thwaites G, et al. Clinical and electrographic manifestations of lesional neocortical temporal lobe epilepsy. Neurology 1997;49:757-763.

26. O'Brien TJ, Kilpatrick C, Murrie V, Vogrin S, Morris K, Cook MJ. Temporal lobe epilepsy caused by mesial temporal sclerosis and temporal neocortical lesions. Brain 1996;119:2133-2141. 